\title{
The potential effect of iron defortification on iron-deficiency anaemia in the US population
}

\author{
Min Tao ${ }^{1, *} \dagger$ David L Pelletier ${ }^{1}$ and Dennis D Miller ${ }^{2}$ \\ 'Division of Nutritional Sciences, Cornell University, Ithaca, NY, USA: ${ }^{2}$ Department of Food Science, \\ Cornell University, Ithaca, NY, USA
}

Submitted 8 May 2006: Accepted 8 January 2007: First published online 24 April 2007

\begin{abstract}
Objective: To quantify the potential effect of iron defortification in the USA on irondeficiency anaemia (IDA).

Methods: Monte Carlo models were built to simulate iron nutrition in the US population. A hypothetical cohort of 15000 persons from the general population was used in 15-year simulations to compare the prevalence of IDA with and without fortification.

Results: With iron fortification, the prevalence of IDA was $2.4 \%$ for children aged 3-5 years, $5.4 \%$ for women aged $20-49$ years, and $0.14 \%$ for men aged $20-49$ years. The corresponding IDA estimates under iron defortification were $4.5 \%, 8.2 \%$ and $0.46 \%$, respectively. Defortification had little effect on the distribution of iron indicators at or above the 50th percentile within each of these three groups and little effect on the distributions of iron indicators among adult men.

Conclusion: Iron defortification is likely to increase IDA among children and women of reproductive age, but is not likely to have meaningful effects on the iron status of men or the majority of women and children.
\end{abstract}

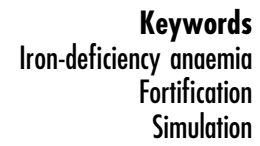

Iron deficiency and anaemia, which affect mainly young children and women of childbearing age, are longstanding public health issues in the USA. According to the Third National Health and Nutrition Examination Survey (NHANES III), iron deficiency anaemia (IDA) per se affected $3 \%$ of children aged $3-5$ years and $2-5 \%$ of adolescent girls and women ${ }^{1}$.

Fortification is generally considered a cost-effective strategy for preventing IDA ${ }^{2-4}$. Many micro-level studies and field trials have shown that fortified food products can improve the iron status of individuals ${ }^{5-11}$. However, results from these studies cannot be directly extrapolated to the national level because the subjects, dietary patterns and other conditions in trials may not reflect conditions in the population at large. For instance, a decline in anaemia has been well-documented among infant and child participants in the US Special Supplemental Nutrition Program for Women, Infants, and Children (WIC) from the late 1970s to the 1990s, coinciding with improvements in the quality and quantity of iron in commonly consumed fortified infant foods ${ }^{4,12-15}$. However, this finding has not been

†Correspondence address: 3311 Toledo Road, Office 6326, Hyattsville, MD 20782 , USA. confirmed in representative national surveys ${ }^{1,16}$. Similarly, macro-level studies based on nationally representative samples are difficult to interpret because fortification or defortification may coincide with other significant changes in food supply, dietary patterns, supplement use and medical care during the same period $^{17,18}$. The present study employs a method that builds upon the strengths of micro- and macro-level approaches to examine the impact of national fortification policy in the USA.

The need for national-level estimates of the impact of fortification policy arises for two reasons. First, there is great interest in fortification as a possible strategy for reducing iron deficiency in developing countries ${ }^{4}$. Second, in developed countries the discovery of genetic subpopulations at risk for iron overload, combined with lower overall levels of iron deficiency than in earlier periods, has raised concerns about the continuation of universal fortification policies ${ }^{19,20}$.

This paper presents the results of a novel method for estimating the national-level effects of iron defortification in the USA. The method, based on Monte Carlo simulation, exploits the strengths of micro- and macro-level approaches by integrating information from varied sources, while also retaining the capacity to separate the 
effects of iron defortification from other features of the food supply and dietary patterns.* The utility of simulation and other systems-based approaches in public health has been noted recently ${ }^{21}$.

\section{Research design and methods}

\section{Model overview}

We developed a Monte Carlo simulation model using @Risk 4.5 for Excel (Palisades Inc.). Monte Carlo simulation is a computer simulation technique that uses sampling from a random number sequence to simulate characteristics or events with probability distributions. A Monte Carlo model of a population is composed of hundreds or thousands of individuals whose aggregated characteristics follow certain distributions. So the simulated model preserves inter-individual variations within the population and allows population-level outcomes to be expressed in probabilistic terms.

The model used for this study generated a representative cohort of the US population composed of 15000 individuals using Monte Carlo sampling. The dynamic changes in total body iron (TBI) of each individual during a 15-year follow-up period were simulated. We tested the impact of iron fortification on iron status and the prevalence of IDA in the cohort.

TBI in the model was composed of three components: iron in haemoglobin $(\mathrm{Hb})$, non-storage iron in tissues and storage iron (Fig. 1). The small amount of transport iron in plasma and extracellular fluid was neglected in the model. During an individual's life, TBI is a changing variable. TBI at a certain time point $\left(t_{i+1}\right)$ in the model is a function of previous iron status $\left(t_{i}\right)$, iron loss and iron absorption during the time period between $t_{i}$ and $t_{i+1}$. Data sources used to define TBI at $t_{0}$, and parameters used to simulate iron absorption and iron loss during various time periods, are listed in Table $1^{22-32}$. Model structure is described in detail below.

\section{Model structure}

To define TBI at baseline $\left(t_{0}\right)$, iron in $\mathrm{Hb}$ was calculated based on Hb level and total blood volume estimated from weight and height, and non-storage iron in tissues estimated from body weight ${ }^{24,33-35}$. Storage iron in tissues was calculated from serum ferritin (SF) level according to the well-documented linear relationship between SF and storage iron ${ }^{36-38}$.

To estimate each individual's TBI at $t_{0}$, his/her age, gender, height, weight, $\mathrm{Hb}$ and SF levels must be defined. NHANES III data were used to generate the empirical

\footnotetext{
"Strictly speaking, this study can only estimate the potential effects of defortification in the USA, rather than the effects of fortification as they may have occurred in earlier decades. This is because the study uses dietary and food supply data from the mid-1990s, reflecting conditions different from those present in earlier decades.
}

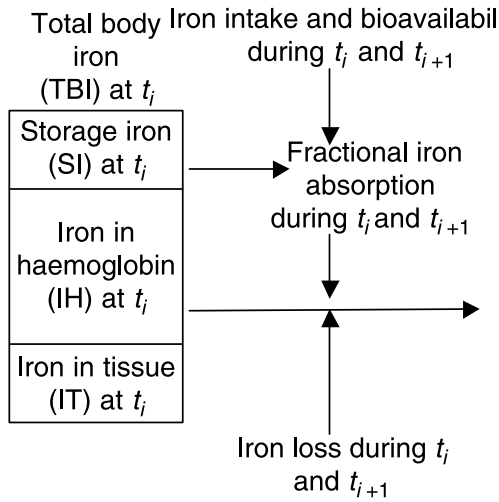

\begin{tabular}{c}
$\begin{array}{c}\text { Total body } \\
\text { iron }\end{array}$ \\
$(\mathrm{TBI})$ at $t_{i+1}$ \\
\hline $\begin{array}{c}\text { Storage iron } \\
(\mathrm{SI}) \text { at } t_{i+1}\end{array}$ \\
\hline $\begin{array}{c}\text { Iron in } \\
\text { haemoglobin } \\
(\mathrm{IH}) \text { at } t_{i+1}\end{array}$ \\
\hline $\begin{array}{c}\text { Iron in tissue } \\
\text { (IT) at } t_{i+1}\end{array}$ \\
\hline
\end{tabular}

Fig. 1 Framework for simulating the dynamic change of iron status

distributions of age and gender ratios for the US population. The population was divided into the following age groups when necessary: <3, 3-6, 6-11, 12-16, $17-20,21-29,30-49,50-59,60-69$ and $\geq 70$ years. For each age and gender group, the distributions of height, weight, Hb and SF were calculated using NHANES III data. Correlation coefficient matrices from the empirical NHANES III data were used to more accurately model the relationships among input variables that were not independent of one another. Monte Carlo sampling was used to generate specific values for these variables for each individual in the model according to these distributions. This procedure generated the starting TBI level for each individual in the cohort.

Two time units were used to facilitate the simulation of changes in iron status once individuals left baseline $\left(t_{0}\right)$ and were projected into the future. The first unit was the month. Events simulated at monthly intervals include iron absorption from food and supplements, daily iron loss and menstruation. Within one simulation month, each individual was assumed to follow the same dietary intake and supplement intake level if they took any iron supplement. Data from the Continuing Survey of Food Intakes by Individuals (CSFII) 1994-96 were used to estimate meat, iron, calcium and ascorbic acid intakes for each gender and age group. Data were normalised using Cox-Box transformations, then analysis of variance was used to estimate average dietary intake levels, intra- and interindividual variations ${ }^{39}$. Using Monte Carlo sampling, specific values were assigned to each individual according to these distributions. An individual's mean intake level of a nutrient for the month was assigned based on the average intake and inter-individual variance for his/her subgroup, then daily intake values were assigned based on each person's mean intake level and intra-individual variance. Linear equations were used to estimate the percentage of dietary iron from fortification based on iron intake from previous work $^{23}$. The same Monte Carlo technique was used to determine whether an individual in the model takes supplements, the average daily dose 
Table 1 Sources of data used in the simulation model

\begin{tabular}{|c|c|}
\hline Variable & Data source \\
\hline Age, gender, height, weight, $\mathrm{Hb}$ level and SF level & NHANES III, ref. 22 \\
\hline Daily iron, vitamin C, calcium and meat intake, iron supplement usage & NHANES III, CSFII 1994-96, ref. 23 \\
\hline $\begin{array}{l}\text { Daily iron loss, iron loss from menses, iron requirement from pregnancy, } \\
\text { blood donations }\end{array}$ & NHANES III, refs 24-27 \\
\hline Iron absorption & Refs $28-30$ \\
\hline Mortality and fertility & Refs 31 and 32 \\
\hline
\end{tabular}

taken, and the length of time that this individual will take iron supplements based on the frequency, dosage and length of iron supplement usage reported in NHANES III.

Iron absorption was determined by meal composition and the individual's iron status. Monsen and Balintfy's model and the regression equation of Hallberg et al. were used to calculate bioavailable iron based on iron intake and the amount of iron-absorption enhancers (ascorbic acid and meat) and iron-absorption inhibitors (calcium) contained in the $\operatorname{diet}^{28,29}$. Data on iron absorption among normal individuals reported by Lynch et al. were analysed to generate the linear regression equations on $\log$ iron absorption rates and SF levels ${ }^{30}$. The equations were used to further adjust the haem and non-haem iron absorption according to each individual's iron store as indicated by SF level. Iron from supplements was assumed to enter the non-haem iron pool in the small intestine, thus its bioavailability was assumed to be the same as non-haem iron from food.

Daily iron loss was assumed to be $14 \mu \mathrm{g}$ per $\mathrm{kg}^{24}$. Average daily loss was calculated according to body weight and iron loss per unit body weight. For adolescent girls older than 11 years and for women of reproductive age in the cohort, the amount of menstrual blood loss per menstrual cycle was assigned based on an empirical distribution $^{27}$. The amount of iron lost each month during menstruation was calculated based on the amount of blood loss and $\mathrm{Hb}$ level. At the end of each month, storage iron was updated, taking into account iron absorption and iron loss during the month. Consequently, the SF level was updated corresponding to the new amount of storage iron.

Year was the second time unit in the simulation model. Events simulated on a yearly interval include growth, blood donations and pregnancy. For children and adolescents, the expected growth was estimated using the 2000 growth curves of the Centers for Disease Control and Prevention ${ }^{22}$. Because of increased height and weight, iron in body tissues expanded and $\mathrm{Hb}$ iron also increased because of increased blood volume and $\mathrm{Hb}$ levels.

Pregnancy was simulated as an event happening within a given simulation year. Iron loss during pregnancy was based on experts' judgement ${ }^{25,26,40}$. The most commonly used distribution to quantify experts' opinions, triangle distribution, was applied. The small loss of iron from breast milk was neglected. The probabilities of giving birth were estimated from national vital statistics and varied according to mother's age $\mathrm{e}^{32}$. Iron supplement usage during pregnancy, the length of taking supplements and the amount of iron taken were simulated based on data from NHANES III. NHANES III data were also used to calculate the probability of being a blood donor for each age and gender group and the frequency of blood donation each year. For blood donors in the simulation model, iron loss through blood donation was calculated using frequency of blood donation per year, units of blood donated each time and $\mathrm{Hb}$ level.

At the end of each simulation year, TBI, $\mathrm{Hb}$ and SF levels were updated as the result of these events. Distributions of TBI were recalculated following the rule that iron in the body is used to build tissue and maintain normal Hb level first before extra iron is stored ${ }^{41}$. Iron in the body was first allocated to body tissues, then to maintain a normal $\mathrm{Hb}$ level. Only after meeting these two needs was the remaining iron apportioned to storage. If the amount of TBI was insufficient to maintain a normal $\mathrm{Hb}$ level, the highest $\mathrm{Hb}$ level possible was calculated.

Mortality rates were obtained from national vital statistics reports. The mortality rates for different gender, age and ethnic groups in 1994 were used in the model ${ }^{31}$. Based on these rates, mortality in various subgroups was randomly assigned.

\section{Verification and validation}

As verification, the computer program was debugged to eliminate logical errors and ensure that the parameters entered into the model were correct. Intermediate simulation outputs, such as simulated one-day nutrient intakes and simulated iron absorption rates, were checked to ensure that the intermediate outputs of the simulation model conformed to general expectations.

Baseline iron status ( $\mathrm{SF}, \mathrm{Hb}$ and TBI at $t_{0}$ ) of the cohort was directly generated from national survey, so it represents the iron status of the US population. However, once individuals in the simulation cohort left baseline, TBI at future times was the result of previous TBI, the algorithm and the parameters used in the model to calculate iron absorption and iron requirements during the interval. Thus, since iron nutrition at the population level in the USA is not subject to dramatic changes from year to year, an important element of validation is whether the 
model can reproduce $\mathrm{Hb}$ and $\mathrm{SF}$ distributions at the end of simulation years. $\mathrm{Hb}$ and $\mathrm{SF}$ levels for each individual at the end of every simulation year were recorded in a data file. The distributions of $\mathrm{Hb}$ and $\mathrm{SF}$ for different gender and age groups in the simulation cohort were calculated and compared with historical data. Since longitudinal data on iron status is very limited, and estimates for the dietary and other input variables reflect conditions in the mid1990s, we chose to use NHANES III data for validation.

\section{Results}

\section{Validation}

In the simulation model, the median TBI after 15 simulation years was $3.4 \mathrm{~g}$ for adult men and $2.2 \mathrm{~g}$ for adult women. This amount is consistent with estimates from experiments ${ }^{25}$. $\mathrm{Hb}$ and $\mathrm{SF}$ were the two other iron status indicators in the simulation model. Figure 2 compares the distributions of $\mathrm{Hb}$ and $\mathrm{SF}$ from the simulation model with empirical data from NHANES III.

Compared with NHANES III data, the difference between simulated and observed $\mathrm{Hb}$ distributions was small. At the 5th and 50th percentiles, the differences between the simulated SF and observed SF were between
0 and $40 \mu \mathrm{gl}^{-1}$ across age and gender groups. The major difference between simulated SF and empirical data was at the 95th percentile. The largest difference was $210 \mu \mathrm{gl}^{-1}$ among females and $343 \mu \mathrm{gl}^{-1}$ among males. In general, variations in $\mathrm{SF}$ in the simulation cohort were less than in the empirical distributions. This may be caused by two factors. First, the simulation model was a simplified version of reality. Some factors that can influence SF levels in the real world were not simulated in the model (e.g. medical treatment, chronic disease and pathological losses of iron). Second, the mismatch between simulation and NHANES III data was most obvious among those with high iron storage, i.e. high SF levels. This may be related to the existence of genetic subpopulations in the USA that were not simulated in this paper, as discussed later.

\section{Iron defortification}

With the iron defortification model, there was no significant decrease of $\mathrm{Hb}$ among women at the 50th and 95th percentiles (Fig. 3). However, at the 5th percentile, $\mathrm{Hb}$ level decreased by 1.5 to $4 \mathrm{gl}^{-1}$ among those aged $1-6$ years and by 7 to $10 \mathrm{gl}^{-1}$ among those aged 10-60 years. This suggests that the majority of women could maintain normal $\mathrm{Hb}$ levels without iron
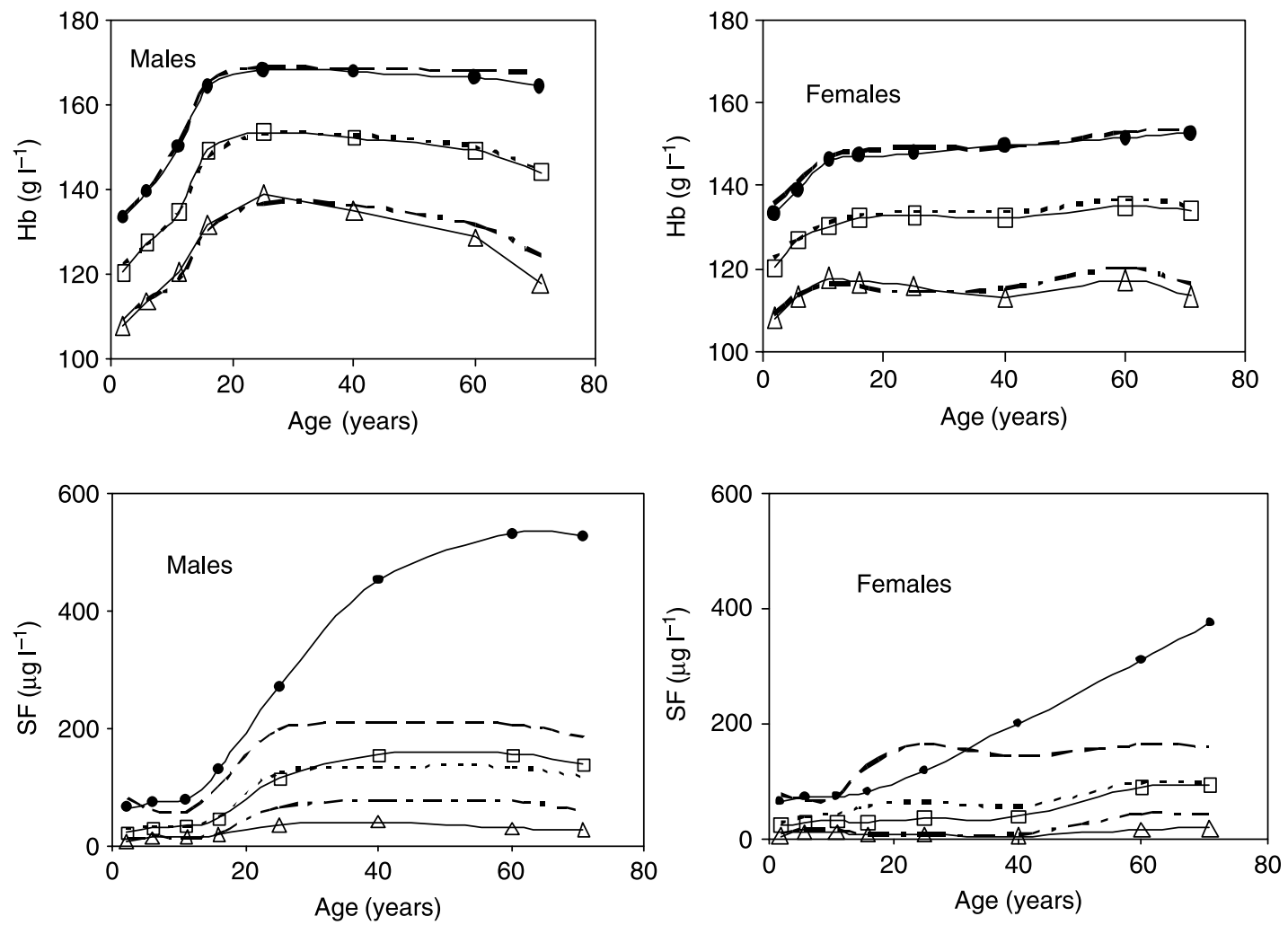

\begin{tabular}{|c|c|c|c|}
\hline $\begin{array}{l}-\because P_{5} \text { simulated } \\
\triangle-P_{5} \text { NHANES III }\end{array}$ & $\begin{array}{l}\because \mathrm{P}_{50} \text { simulated } \\
\square-\mathrm{P}_{50} \text { NHANES III }\end{array}$ & -- & $\begin{array}{l}\mathrm{P}_{95} \text { simulated } \\
\mathrm{P}_{95} \text { NHANES III }\end{array}$ \\
\hline
\end{tabular}

Fig. 2 Distributions of haemoglobin ( $\mathrm{Hb})$ and serum ferritin (SF) among males and females, comparing 15-year simulation results with data from the Third National Health and Nutrition Examination Survey (NHANES III). $P_{5}-5$ th percentile; $P_{50}-50$ th percentile (median); $\mathrm{P}_{95}$ - 95th percentile 

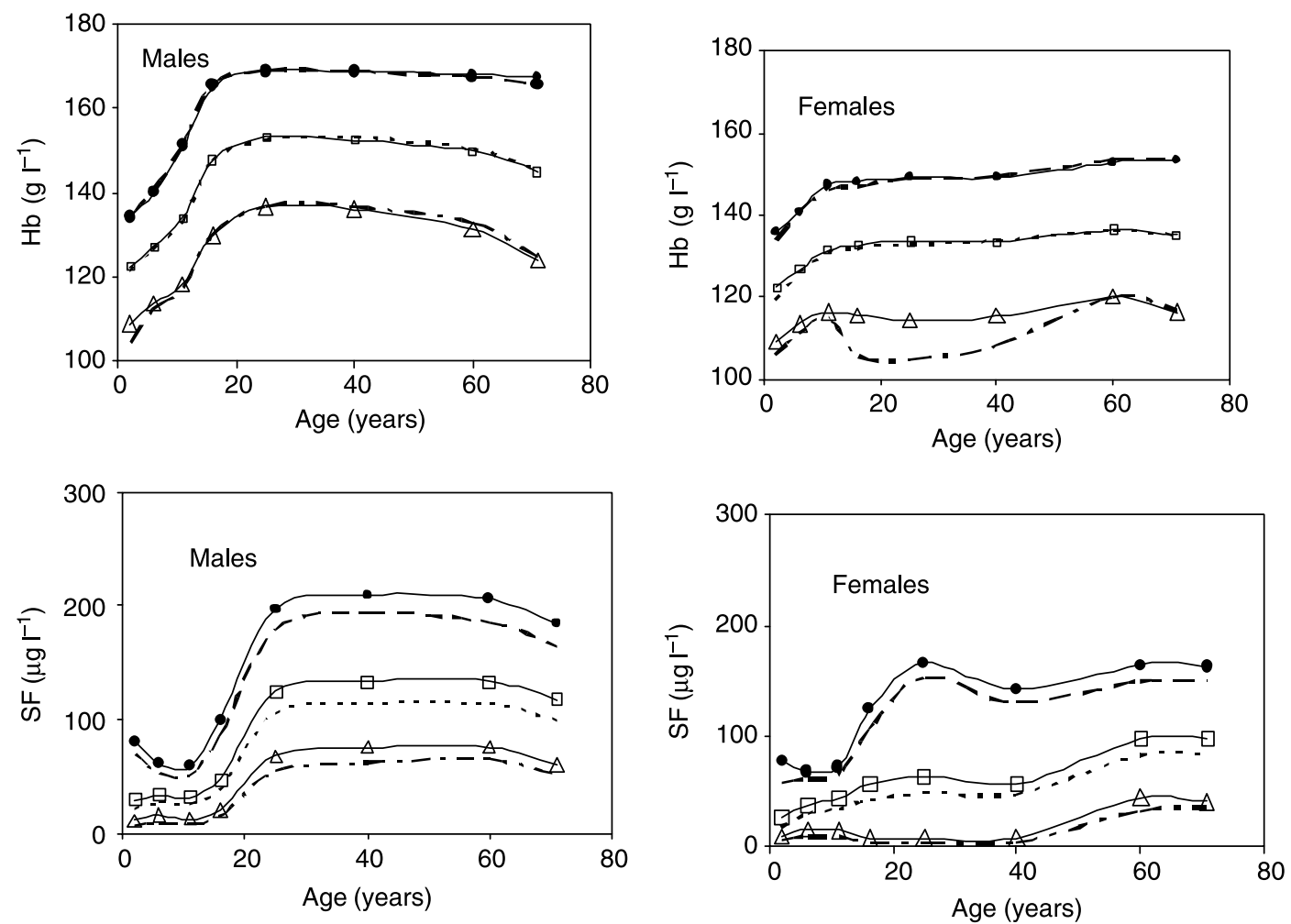

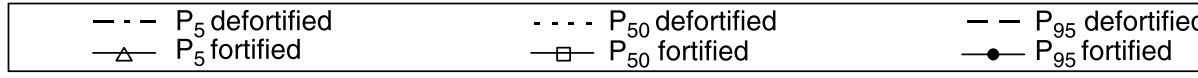

Fig. 3 Distributions of haemoglobin $(\mathrm{Hb})$ and serum ferritin (SF) among males and females under iron fortification and iron defortification. $P_{5}-5$ th percentile; $P_{50}-50$ th percentile (median); $P_{95}-95$ th percentile

fortification, but a small percentage at the low end of the distribution would experience a decrease in $\mathrm{Hb}$ levels when their iron intake decreases due to defortification. Among males, there was no detectable change in $\mathrm{Hb}$ distributions after iron fortification.

Figure 3 shows a systematic decrease in SF levels among both males and females with iron defortification. Among children, the decrease in SF ranged from 4 to $13 \mu \mathrm{gl}^{-1}$; among adolescent boys and adult men, from 10 to $20 \mu \mathrm{g} 1^{-1}$.

The prevalence of IDA was estimated based on the simulated $\mathrm{Hb}$ and SF values. With iron fortification, the prevalence of IDA in the simulation model was similar to the prevalence of IDA observed in NHANES III data (Table 2). A difference of approximately $2 \%$ in the prevalence was found between the simulation model and NHANES III among children less than 3 years old, in females between 12 and 49 years of age and among adults older than 50 years. Without iron fortification, the increase in IDA was most significant among children and women of reproductive age. Among children less than 11 years old, the prevalence of IDA increased by about 2 to 4.5\%. For girls between 12 and 15 years of age, the prevalence increased by $3.8 \%$; similarly, for women between 20 and 49 years, the prevalence increased by
3.7\%. The increase was most dramatic (more than 5\%) among 16- to 19-year-old girls. Further analysis (not shown) revealed that $45-89 \%$ of the excess cases of IDA in various age groups are in the mild category $(\mathrm{Hb}>100$

Table 2 Prevalence of IDA with and without iron fortification

\begin{tabular}{lccc}
\hline & & \multicolumn{2}{c}{$\begin{array}{c}\text { Prevalence }(\%)(95 \% \mathrm{Cl}) \\
\text { from simulation models }\end{array}$} \\
\cline { 3 - 4 } Age and gender & $\begin{array}{c}\text { NHANES } \\
\text { III }(\%)^{*}\end{array}$ & $\begin{array}{l}\text { Iron fortification } \\
\text { Iron defortification }\end{array}$ \\
\hline Both sexes & & & \\
$<3$ years & 3 & $1.13(0.15-2.12)$ & $4.15(2.37-5.93)$ \\
$3-5$ years & $<1$ & $0.86(0.51-1.21)$ & $5.33(4.49-6.16)$ \\
$6-11$ years & $<1$ & $0.57(0.44-0.71)$ & $2.60(2.31-3.89)$ \\
Males & & & \\
$12-15$ years & $<1$ & $1.02(0.77-1.27)$ & $2.76(2.45-3.17)$ \\
$16-19$ years & $<1$ & $0.21(0.10-0.31)$ & $0.73(0.52-0.93)$ \\
$20-49$ years & $<1$ & $0.02(0.01-0.03)$ & $0.04(0.02-0.06)$ \\
$50-69$ years & 1 & $0.03(0.01-0.05)$ & $0.03(0.01-0.05)$ \\
$\geq 70$ years & 2 & $0.00(0.00-0.04)$ & $0.01(0.00-0.03)$ \\
Females & & & \\
$12-15$ years & 2 & $3.36(2.91-3.81)$ & $7.21(6.57-7.84)$ \\
$16-19$ years & 3 & $5.08(4.56-5.59)$ & $10.37(9.60-11.10)$ \\
$20-49$ years & 5 & $4.52(4.34-4.70)$ & $8.25(8.02-8.49)$ \\
$50-69$ years & 2 & $0.30(0.23-0.37)$ & $0.83(0.72-0.95)$ \\
$\geq 70$ years & 2 & $0.22(0.13-0.31)$ & $0.60(0.46-0.74)$ \\
\hline
\end{tabular}

IDA - iron-deficiency anaemia; NHANES III - Third National Health and Nutrition Examination Survey; $\mathrm{Cl}$ - confidence interval.

* Data source: ref. 1. 
$\left.\mathrm{gl}^{-1}\right), 10-39 \%$ are in the moderate category $(\mathrm{Hb}=70-$ $\left.100 \mathrm{gl}^{-1}\right)$ and less than $17 \%$ are severe $\left(\mathrm{Hb}<70 \mathrm{gl}^{-1}\right)^{42}$. Adolescent boys, adult men and women after menopause were at lowest risk for IDA, with prevalence of less than $1 \%$ after iron defortification.

\section{Discussion}

The primary findings from this study are that, under the dietary patterns, nutrient intake levels and other conditions in the mid-1990s in the USA, iron defortification would: (1) lead to a modest decrease in iron stores in all age/sex groups, as seen in SF levels - this effect is seen at all centiles of the distribution examined; (2) decrease Hb levels (and increase IDA levels) among the most vulnerable groups (young children and adolescent and reproductive-aged women) - this effect is seen only at the lower end of the distribution in these groups, where the need is greatest; and (3) have smaller but detectable effects in increasing IDA among prepubescent children and adolescent boys, with no effect on the $\mathrm{Hb}$ levels of adult men.

As with all simulations, the validity of these results depends upon the accuracy of the input variables, the parameters defining key relationships among the variables and the structure of the biological model. In the present case, the strengths of the study include the use of nationally representative data to estimate the distributions for many of the input variables and the existence of a substantial literature concerning the biology of iron nutrition from which key model parameters were derived. In addition, several aspects of the empirical results provide some confidence in the model. First, the model is able to reproduce the observed national distributions of $\mathrm{SF}$ and $\mathrm{Hb}$ (Fig. 2). Second, the one notable discrepancy between simulated and observed distributions (i.e. the 95th percentile for SF in Fig. 2) has a plausible explanation based on current knowledge. Specifically, the SF distribution observed in NHANES III data reflects the presence of genetic subpopulations at risk for iron overload, but these subpopulations were not included in the simulation model presented here. Although less than $0.5 \%$ of the US population is homozygous for the C282Y mutation (the variant most strongly associated with haemochromatosis), approximately $9 \%$ of the population is heterozygous for this mutation $^{43}$ and have been shown to have elevated SF and transferrin saturation levels ${ }^{44,45}$.

It is noteworthy that the present simulation model produces plausible and coherent results despite some limitations in input variables and parameter estimates. For instance: (1) the nutrient intake distributions were adjusted for intra-individual variation using standard methods ${ }^{39}$ but it was not possible to model how individuals' relative position in the distribution may change during their lifetime; (2) fractional iron absorption was adjusted for some known influences (ascorbic acid, meat, calcium and haem iron) but not others (e.g. phytate, tannins); and
(3) fractional absorption rates (and inter-individual variation in these rates) were estimated from a relatively small number of studies with a limited range of variation in age, gender, meal conditions and iron status. The ability of the model to produce plausible results despite these limitations may relate to the strong homeostatic properties of iron status across a wide range of intakes, the focus on population- rather than individual-level changes and the inclusion of the major determinants of iron status in the model (with the exception of genetic variants).

Our simulation results differ from an observational study in Denmark, which reported iron nutrition among Danish adults above the age of 40 years before and after Denmark ended its mandatory iron fortification policy in 1987. That study is important because few researchers have used national representative samples to address this issue and few countries have undertaken defortification. Unlike our simulation results, the Danish study found no increase in iron deficiency after defortification. Among menopausal women and adult men, SF levels even showed some increase $\mathrm{e}^{17,18,20,46,47}$. However, the impact of confounders could not be excluded in these observational studies. As the authors noted, the decrease in iron intake after defortification coincided with less consumption of dairy products, eggs and tea, and greater consumption of meat and poultry ${ }^{17,18}$. These concomitant dietary changes may have compensated for the decrease in iron intake due to defortification or, alternatively, population iron status may not be as strongly influenced by fortification as is generally assumed. These confounding factors are a major reason why observational studies provide a limited basis for evaluating the effectiveness of national fortification programmes and illustrate the utility of microsimulation methods as a means for separating the effects of fortification or defortification from other changes at the national level.

In addition to these methodological differences, the US and Danish populations differ in key aspects of their diet and food supply. The US population has substantially higher dietary iron intake and iron fortification levels, with a much lower percentage of women taking iron supplements $^{17,48}$. Thus food appears to be a more important source of iron in the USA than in Denmark, and iron fortification represents a higher fraction of total iron intake, such that fortification may be a more important determinant of iron nutrition in the USA than in Denmark.

Sweden is another country that withdrew iron fortification of flour in 1995. The preliminary result from Sweden is more consistent with our simulation results. One study in Swedish schools showed that iron deficiency increased from $39.6 \%$ in 1994 to $48.9 \%(P<0.001)$ in year 2000 among adolescent girls and iron defortification was suggested to be the main cause for the increase iron deficiency ${ }^{49}$. Further results from the Swedish study are needed to understand the similarities and differences between the Swedish and Danish experiences and the simulated model of the US population. 


\section{Conclusion}

Estimating the effects of fortification policy is problematic because neither micro- nor macro-level studies, by themselves, provide firm answers. This paper improves upon previous studies by using a method that integrates information from micro- and macro-level studies and retains the capacity to separate the effects of iron fortification from other features of the food supply and dietary patterns. The study suggests that defortification in the USA would increase IDA by 2 to 5 percentage points among pre-school and prepubescent children, adolescent girls and women of reproductive age. However, in the majority of women, children and men, defortification would not change Hb levels and would decrease iron stores by an amount unlikely to have public health implications.

It is important to note that the present simulation does not examine the potential influence of changes in health care, the WIC programme, targeted fortification or other factors in preventing or ameliorating the rise in IDA among vulnerable groups, nor the cost-effectiveness of such approaches compared with fortification. The policy implications of the present findings depend upon such considerations and could be informed through further simulations that examine these issues. In addition, the policy implications depend on the extent to which defortification might slow the progression of iron overload and its sequelae, as discussed in a separate paper ${ }^{42}$.

\section{Acknowledgements}

Sources of funding: M.T. was funded by scholarship from the Division of Nutritional Sciences, Cornell University. This work was partly funded by an unrestricted education grant to Cornell University by the Merck Company Foundation, the philanthropic arm of Merck \& Co. Inc.

Conflict of interest declaration: The authors have no conflicts of interest.

Authorship responsibilities: M.T. developed the simulation model and prepared the manuscript. D.L.P. initiated the overall project of which this paper is a part, worked closely with M.T. in developing the conceptual underpinnings of the model and interpreting model results, and participated in drafting the paper. D.D.M. worked with M.T. in developing the model and interpreting model results, and participated in preparing the paper.

\section{References}

1 Looker AC, Dallman PR, Carroll MD, Gunter EW, Johnson CL. Prevalence of iron deficiency in the United States. JAMA: Journal of the American Medical Association 1997; 277(12): 973-6.

2 American Academy of Pediatrics Committee on Nutrition. Iron fortification of infant formulas. Pediatrics 1999; 104(1 Pt 1): 119-23.
3 Baltussen R, Knai C, Sharan M. Iron fortification and iron supplementation are cost-effective interventions to reduce iron deficiency in four subregions of the world. Journal of Nutrition 2004; 134(10): 2678-84.

4 Yip R, Ramakrishnan U. Experiences and challenges in developing countries. Journal of Nutrition 2002; 132(Suppl. 4): 827S-30S.

5 Torrejon CS, Castillo-Duran C, Hertrampf ED, Ruz M. Zinc and iron nutrition in Chilean children fed fortified milk provided by the Complementary National Food Program. Nutrition 2004; 20(2): 177-80.

6 Stekel A, Olivares M, Cayazzo M, Chadud P, Llaguno S, Pizarro F. Prevention of iron deficiency by milk fortification. II. A field trial with a full-fat acidified milk. American Journal of Clinical Nutrition 1988; 47(2): 265-9.

7 Thuy PV, Berger J, Davidsson L, Khan NC, Lam NT, Cook JD, et al. Regular consumption of NaFeEDTA-fortified fish sauce improves iron status and reduces the prevalence of anemia in anemic Vietnamese women. American Journal of Clinical Nutrition 2003; 78(2): 284-90.

8 Zimmermann MB, Zeder C, Chaouki N, Saad A, Torresani T, Hurrell RF. Dual fortification of salt with iodine and microencapsulated iron: a randomized, double-blind, controlled trial in Moroccan schoolchildren. American Journal of Clinical Nutrition 2003; 77(2): 425-32.

9 Viteri FE, Alvarez E, Batres R, Torun B, Pineda O, Mejia LA, et al. Fortification of sugar with iron sodium ethylenediaminotetraacetate (FeNaEDTA) improves iron status in semirural Guatemalan populations. American Journal of Clinical Nutrition 1995; 61(5): 1153-63.

10 Layrisse M, Chaves JF, Mendez C, Bosch V, Tropper E, Bastardo B, et al. Early response to the effect of iron fortification in the Venezuelan population. American Journal of Clinical Nutrition 1996; 64(6): 903-7.

11 Sari M, Bloem MW, de Pee S, Schultink WJ, Sastroamidjojo S. Effect of iron-fortified candies on the iron status of children aged 4-6y in East Jakarta, Indonesia. American Journal of Clinical Nutrition 2001; 73(6): 1034-9.

12 Sherry B, Mei Z, Yip R. Continuation of the decline in prevalence of anemia in low-income infants and children in five states. Pediatrics 2001; 107(4): 677-82.

13 Yip R, Binkin NJ, Fleshood L, Trowbridge FL. Declining prevalence of anemia among low-income children in the United States. JAMA: Journal of the American Medical Association 1987; 258(12): 1619-23.

14 Miller V, Swaney S, Deinard A. Impact of the WIC program on the iron status of infants. Pediatrics 1985; 75(1): 100-5.

15 Vazquez-Seoane P, Windom R, Pearson HA. Disappearance of iron-deficiency anemia in a high-risk infant population given supplemental iron. New England Journal of Medicine 1985; 313(19): 1239-40

16 Centers for Disease Control and Prevention. Iron deficiency - United States, 1999-2000. MMWR Morbidity and Mortality Weekly Report 2002; 51(40): 897-9.

17 Milman N, Byg KE, Ovesen L, Kirchhoff M, Jurgensen KS. Iron status in Danish women, 1984-94: a cohort comparison of changes in iron stores and the prevalence of iron deficiency and iron overload. European Journal of Haematology 2003; 71(1): 51-61.

18 Milman N, Byg KE, Ovesen L, Kirchhoff M, Jurgensen KS. Iron status in Danish men 1984-94: a cohort comparison of changes in iron stores and the prevalence of iron deficiency and iron overload. European Journal of Haematology 2002; 68(6): 332-40.

19 Osler M, Milman N, Heitmann BL. Consequences of removing iron fortification of flour on iron status among Danish adults: some longitudinal observations between 1987 and 1994. Preventive Medicine 1999; 29(1): 32-6.

20 Olsson KS, Vaisanen M, Konar J, Bruce A. The effect of withdrawal of food iron fortification in Sweden as studied 
with phlebotomy in subjects with genetic hemochromatosis. European Journal of Clinical Nutrition 1997; 51(11): 782-6.

21 McLeroy K. Thinking of systems. American Journal of Public Health 2006; 96(3): 402.

22 Kuczmarski RJ, Ogden CL, Guo SS, Grummer-Strawn LM, Flegal KM, Mei Z, et al. CDC Growth Charts for the United States: methods and development. Vital and Health Statistics. Series 11, Data from the national health survey 2002; (246): 1-190.

23 Berner LA, Clydesdale FM, Douglass JS. Fortification contributed greatly to vitamin and mineral intakes in the United States, 1989-1991. Journal of Nutrition 2001; 131(8): 2177-83.

24 Standing Committee on the Scientific Evaluation of Dietary Reference Intakes, Food and Nutrition Board, Institute of Medicine. Dietary Reference Intakes for Vitamin A, Vitamin K, Arsenic, Boron, Chromium, Copper, Iodine, Iron, Manganese, Molybdenum, Nickel, Silicon, Vanadium and Zinc. Washington, DC: National Academies Press, 2000.

25 Bothwell THCR, Cook JD, Finch CA. Iron Metabolism in Man. St. Louis, MO: Blackwell Scientific Publications, 1979.

26 Bothwell TH. Iron requirements in pregnancy and strategies to meet them. American Journal of Clinical Nutrition 2000; 72(Suppl.1): 257S-64S.

27 Hallberg L, Hogdahl AM, Nilsson L, Rybo G. Menstrual blood loss - a population study. Variation at different ages and attempts to define normality. Acta Obstetrica et Gynecologica Scandinavica 1966; 45(3): 320-51.

28 Monsen ER, Balintfy JL. Calculating dietary iron bioavailability: refinement and computerization. Journal of the American Dietetic Association 1982; 80(4): 307-11.

29 Hallberg L, Brune M, Erlandsson M, Sandberg AS, RossanderHulten L. Calcium: effect of different amounts on nonhemeand heme-iron absorption in humans. American Journal of Clinical Nutrition 1991; 53(1): 112-9.

30 Lynch SR, Skikne BS, Cook JD. Food iron absorption in idiopathic hemochromatosis. Blood 1989; 74(6): 2187-93.

31 National Center for Health Statistics. Death rates for selected causes by 10-year age groups, race and sex in the United States, 1979-98 [online]. Available at http://www.cdc.gov/ nchs/datawh/statab/unpubd/mortabs/hist290.htm. Accessed 11 April 2006.

32 Ventura SJ, Mosher WD, Curtin SC, Abma JC, Henshaw S. Trends in pregnancies and pregnancy rates by outcome: estimates for the United States, 1976-96. Vital and Health Statistics. Series 21, Data on natality, marriage, and divorce 2000(56): $1-47$.

33 Linderkamp O, Versmold HT, Riegel KP, Betke K. Estimation and prediction of blood volume in infants and children. European Journal of Pediatrics 1977; 125(4): 227-34.

34 Mollison P. Blood Transfusion in Clinical Medicine. Boston, MA: Blackwell Scientific Publications, 1983.

35 Nadler SBHJ, Bloch T. Prediction of blood volume in normal human adults. Surgery 1962; 51: 224-32.
36 Hallberg L, Rossander-Hulten L. Iron requirements in menstruating women. American Journal of Clinical Nutrition 1991; 54(6): 1047-58.

37 Hallberg L. Perspectives on nutritional iron deficiency. Annual Review of Nutrition 2001; 21: 1-21.

38 Hallberg L, Hulthen L, Garby L. Iron stores in man in relation to diet and iron requirements. European Journal of Clinical Nutrition 1998; 52(9): 623-31.

39 Subcommittee on Criteria for Dietary Evaluation, Coordinating Committee on Evaluation of Food Consumption Surveys, Food and Nutrition Board, National Research Council. Nutrient Adequacy: Assessment using Food Consumption Surveys. Washington, DC: National Academies Press, 1986.

40 Hallberg L. Iron balance in pregnancy. In: Berger $\mathrm{H}$, ed. Vitamins and Minerals in Pregnancy and Lactation. New York: Vevey/Raven Press, Ltd, 1988; 115-27.

41 Brock JH, Halliday JW, Pippard MJ, Powell LW. Iron Metabolism in Health and Disease. Philadelphia, PA: WB Saunders Company Ltd, 1994.

42 Tao M. Using microsimulation to evaluate policy issues on hereditary hemochromatosis: a case study for gene-nutrient interactions. Thesis, Cornell University, Ithaca, NY, 2005.

43 Hanson $\mathrm{EH}$, Imperatore G, Burke W. HFE gene and hereditary hemochromatosis: a HuGE review. Human Genome Epidemiology. American Journal of Epidemiology 2001; 154(3): 193-206.

44 Mura C, Le Gac G, Raguenes O, Mercier AY, Le Guen A, Ferec C. Relation between HFE mutations and mild iron-overload expression. Molecular Genetics and Metabolism 2000; 69(4): 295-301.

45 Cogswell ME, Gallagher ML, Steinberg KK, Caudill SP, Looker AC, Bowman BA, et al. HFE genotype and transferrin saturation in the United States. Genetics in Medicine 2003; 5(4): 304-10.

46 Milman N, Pedersen AN, Ovesen L, Schroll M. Iron status in 358 apparently healthy 80 -year-old Danish men and women: relation to food composition and dietary and supplemental iron intake. Annals of Hematology 2004; 83(7): 423-9.

47 Milman N, Byg KE, Ovesen L. Iron status in Danes 1994. II: Prevalence of iron deficiency and iron overload in 1319 Danish women aged 40-70 years. Influence of blood donation, alcohol intake and iron supplementation. Annals of Hematology 2000; 79(11): 612-21.

48 Cogswell ME, Kettel-Khan L, Ramakrishnan U. Iron supplement use among women in the United States: science, policy and practice. Journal of Nutrition 2003; 133(6): 1974S-7S.

49 Hulthén L, Hallberg L. Increased prevalence of iron deficiency due to withdrawal of iron fortification of flour in Sweden. In: Reports of the 2004 International Nutritional Anemia Consultative Group Symposium. Washington, DC: ILSI Human Nutrition Institute, 2005; 63. 